\title{
Liver X Receptor $\alpha$ Inhibits Osteosarcoma Cell Proliferation through Up-Regulation of FoxO1
}

\author{
Yue-wen Chang ${ }^{\text {Y Yong-fang Zhao }}$ Yue-long Cao ${ }^{a}$ Xin-feng Gua Zhi-qiang Lia \\ Shu-qiang Wang ${ }^{a}$ Jin-hao Miao ${ }^{a}$ Hong-sheng Zhan ${ }^{a}$ \\ aDepartment of Orthopedics and Traumatology, Shuguang hospital affiliated to Shanghai University of \\ Traditional Chinese Medicine, China
}

\section{Key Words}

Osteosarcoma $\cdot \mathrm{LXR} \alpha \cdot \mathrm{FoxO} \cdot$ Transcription

\begin{abstract}
Background: Osteosarcoma is the most common primary bone malignancy of adolescents and young adults. Methods: We analyzed liver X receptor $\alpha$ (LXR $\alpha)$ mRNA expression in 16 pairs of human osteosarcoma tissues and adjacent noncancerous tissues. Moreover, we investigated LXR $\alpha$ 's potential role in regulating cell proliferation in Saos-2 and U2OS cells. Results: We found that activation of $L X R \alpha$, a member of nuclear receptor, was able to inhibit cell proliferation in Saos-2 and U2OS cells. At the molecular level, our results further revealed that expression of tumor suppressor gene, FoxO1, was up-regulated by LXR $\alpha$ activation. LXR $\alpha$ activates FoxO1 transcription through a direct binding on its promoter region. Conclusion: LXR $\alpha$ acts as a tumor suppressor for osteosarcoma, which may offer a new way in molecular targeting cancer treatment.

\section{Introduction}

Osteosarcoma is the most common primary bone malignant tumor. Similar to other tumors, osteosarcoma is a complicated disease with multi-genetic variations $[1,2]$. Therefore, investigations on gene regulation networks are helpful for further understanding the mechanism governing the initiation and progression of osteosarcoma [3].

Liver X Receptors (LXR $\alpha$ and LXR $\beta$ ) are members of nuclear receptors initially isolated in the liver and activated by cholesterol derivatives, the oxysterols $[4,5]$. LXR $\beta$ expression 
is accepted to be rather ubiquitous, while LXR $\alpha$ is more restricted and mainly expressed in liver, intestine, white adipose tissue and macrophages [3-5]. The fundamental role of LXR $\alpha$ is to control cholesterol homeostasis. Large amount of cholesterol ester rapidly accumulated in the liver in LXR $\alpha$ null mice fed a high cholesterol diet [6, 7]. Besides, these mice developed an impaired bile acid homeostasis due to a default in the expression of the cholesterol 7a-hydroxylase (Cyp7A1), a key enzyme essential in bile acid synthesis [6, 7].

Recent studies have also suggested that LXR $\alpha$ plays important roles in the regulation of tumorigenesis. It was shown that LXR $\alpha$ could associate with Hepatitis B virus X protein $(\mathrm{HBx})$, which represents an important mechanism explaining $\mathrm{HBx}$-induced hepatic lipogenesis during HBV-associated hepatic carcinogenesis [8]. Besides, LXR was shown to suppress mRNA and (or) protein expression of Skp2, cyclin A2, cyclin D1 and estrogen receptor (ER) alpha, whereas it increased the p53 protein level and maintained the $\mathrm{Rb}$ protein in a hypophosphorylated active form in several human breast cancer cells lines $[9,10]$. Moreover, LXR $\alpha$ suppressed proliferation in the colon cancer [11]. LXR $\alpha$ agonist treatment also reduced the percentage of the cell population in S-phase and caused G(1) cell cycle arrest in prostate cancer cells [12-14]. However, whether LXR affects osteosarcoma progression remains unknown.

\section{Materials and Methods}

\section{Cell culture and tissue samples}

Osteosarcoma cell lines were obtained from American Type Culture Collection (Rockville, MD). Cells were culture in Dulbecco's modified Eagle's medium (DMEM, Gibco, Beijing) supplemented with $10 \%$ fetal bovine serum (Gibco, Beijing). Tumor tissues and adjacent normal tissues were collected from routine therapeutic surgery at our department. All samples were obtained with informed consent and approved by the hospital institutional review board.

\section{Real-time PCR}

Total RNA from tissue samples and cell lines was isolated by TRIzol reagent. The extracted RNA was quantified using an ND-1000 spectrophotometer (Nanodrop, Wilmington), and complementary singlestrand DNA was synthesized using an Omniscript RT kit (Qiagen, Valencia). Real-time PCR was performed using a SYBR Green Premix Ex Taq (Takara) on Light Cycler 480 (Roche). The interested transcripts expression was normalized to GAPDH mRNA expression using the $\Delta \mathrm{Ct}$ method and the linearized $\Delta \mathrm{Ct}$ (i.e. $2-\Delta \mathrm{Ct}$ ) was used for comparative purposes. The primer sequences were available upon request.

\section{Plasmid construction, transfection and Luciferase reporter assay}

Human Fox01 promoter was amplified from the human genomic DNA template and inserted into pGL4.15 basic vector (Promega). Mutant LXR binding motif was generated using a PCR mutagenesis kit (Toyobo). All the transient transfections were performed by Lipofectamine 2000 (Invitrogen), according to the manufacturer's instructions. For luciferase reporter assays, cells were seeded in 24-well plates and transfected with the indicated plasmids. Luciferase activities were measured using the Dual Luciferase Reporter Assay System (Promega).

\section{BrdU Assays}

A cell proliferation enzyme-linked immunosorbent assay (BrdU kit; Beyotime) was used to analyze the incorporation of BrdU during DNA synthesis following the manufacturer's protocols. All experiments were performed in triplicate. Absorbance was measured at $450 \mathrm{~nm}$ in the Spectra Max 190 ELISA reader (Molecular Devices, Sunnyvale, CA).

\section{Western blot}

Cells or tissues were harvested and lysed with ice-cold lysis buffer $(50 \mathrm{mM}$ Tris- $\mathrm{HCl}, \mathrm{pH}$ 6.8, 100 $\mathrm{mM} 2-\mathrm{ME}, 2 \% \mathrm{w} / \mathrm{v}$ SDS, $10 \%$ glycerol). After centrifugation at $20000 \times \mathrm{g}$ for $10 \mathrm{~min}$ at $4{ }^{\circ} \mathrm{C}$, proteins in the supernatants were quantified and separated by $10 \%$ SDS PAGE, transferred to NC membrane. After blocking 
A

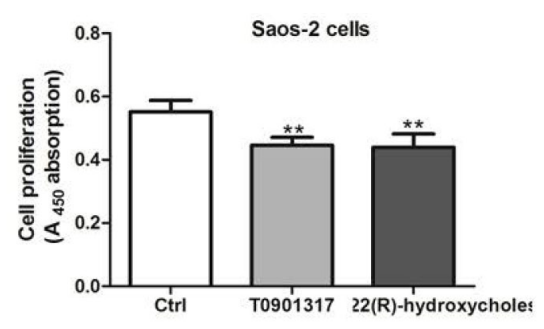

B

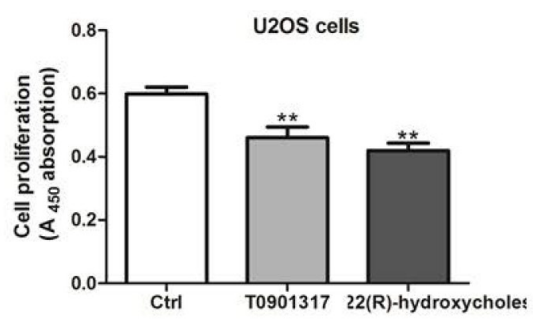

Fig. 1. LXR $\alpha$ activation inhibits osteosarcoma cell proliferation. (A-B) The cell proliferative potential (BrdU) was determined in Saos-2 and U20S cells treated with vehicle control (Ctrl), T0901317 or 22(R)-hydroxycholesterol. A450 absorption was assayed after treatment for $24 \mathrm{hr}$.

A

Saos-2 Cells

SIRNA NC LXR $\alpha$

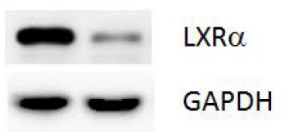

C

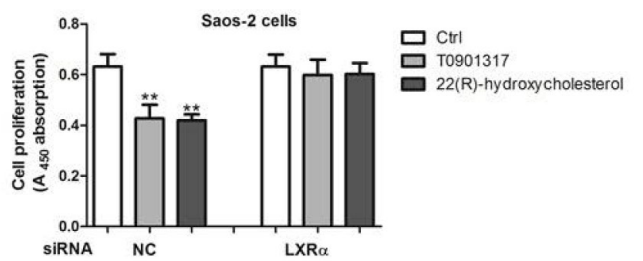

B

U2OS Cells

SIRNA NC LXR $\alpha$

$\longrightarrow$ LXR $\alpha$

- GAPDH

D

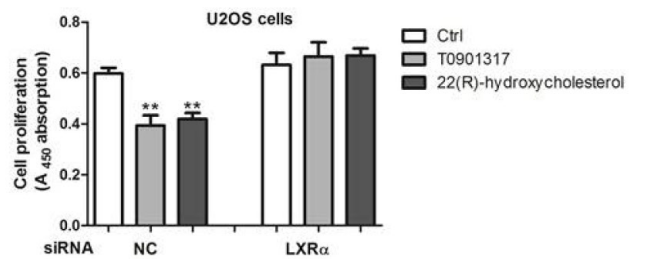

Fig. 2. LXR $\alpha$ deficiency abolished the roles of T0901317 and 22(R)-hydroxycholesterol. (A-B) Western blot analysis fo LXR $\alpha$ in the Saos-2 and U2OS cell transfected with siRNA oligos targeting LXR or negative control (NC). (C-D) The cell proliferative potential (BrdU) was determined in Saos-2 and U2OS cells.

with $10 \%$ nonfat milk in PBS, membranes were immunoblotted with antibodies as indicated, followed by HRP-linked secondary antibodies (Cell Signaling). The signals were detected by SuperSignal West Pico Chemiluminescent Substrate kit (Pierce, Rockford, IL) according to manufacturer's instructions. Anti-LXR, -p27, p21 and Fox01 antibodies were purchased from Abcam (USA). Protein levels were normalized to total GAPDH (Santa Cruz, USA).

\section{Statistical analysis}

Data are expressed as the mean \pm SEM from at least three separate experiments. Differences between groups were analyzed using Student's t-test. A value of $p<0.05$ was considered statistically significant.

\section{Results}

LXR $\alpha$ activation inhibited cell proliferation

In order to assess the effects of LXR $\alpha$ on osteosarcoma cell growth, Saos- 2 were treated with LXR $\alpha$ agonist: T0901317 and 22-hydroxycholesterol. As shown in Figure 1A, both compounds repressed proliferation in Saos-2 cells (Fig. 1A). Besides, we observed a similar result in U2OS cells (Fig. 1B). 
Fig. 3. LXR $\alpha$ upregulates expression of the cell-cycle inhibitors p27 and p21. (A-B) mRNA and protein levels of p27 and p21 in Saos-2 cells treated with vehicle control (Ctrl), T0901317 or 22(R)-hydroxycholesterol. (C-D) mRNA and protein levels of p27 and p21 in U20S cells treated with vehicle control (Ctrl), T0901317 or 22(R)-hydroxycholesterol.

Fig. 4. $\operatorname{LXR} \alpha$ upregulates expression of Fox01. (A-B) mRNA and protein levels of Fox01 in Saos-2 cells treated with vehicle control (Ctrl) or T0901317. (C-D) mRNA and protein levels of FoxO1 in U20S cells treated with vehicle control (Ctrl) or T0901317.

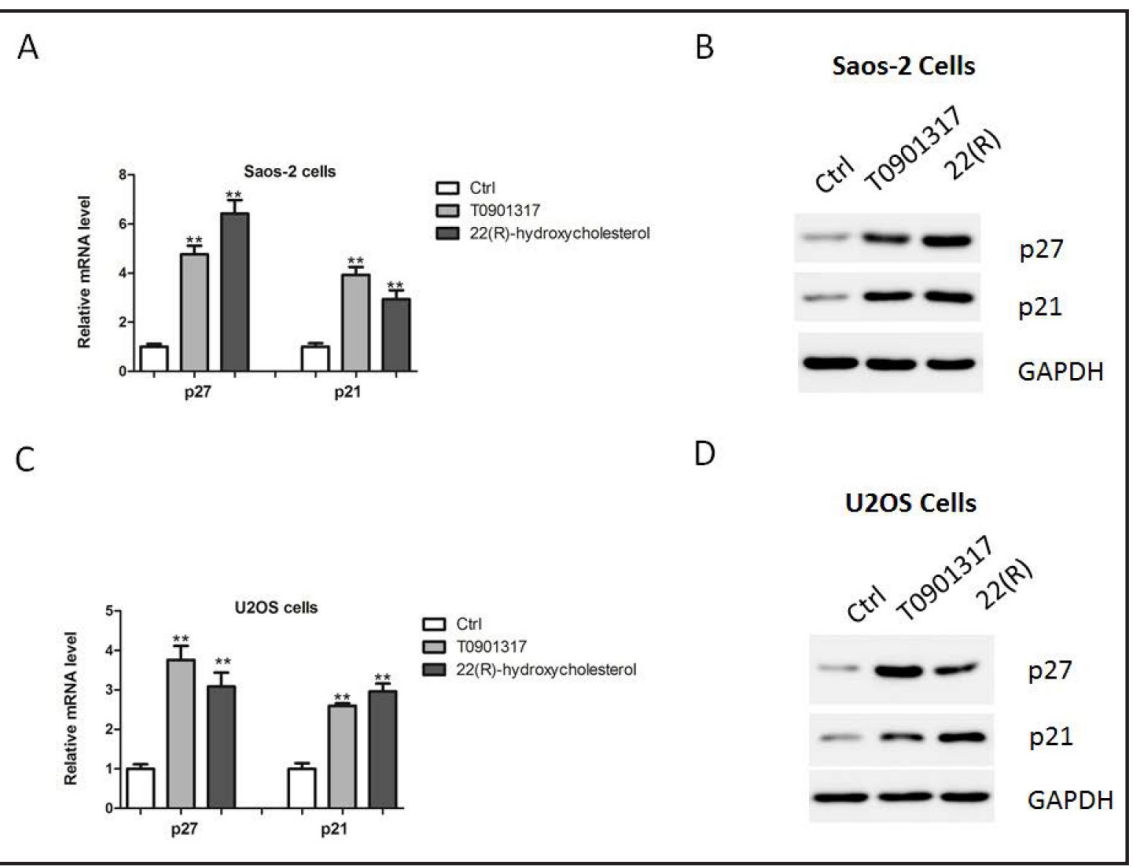

A

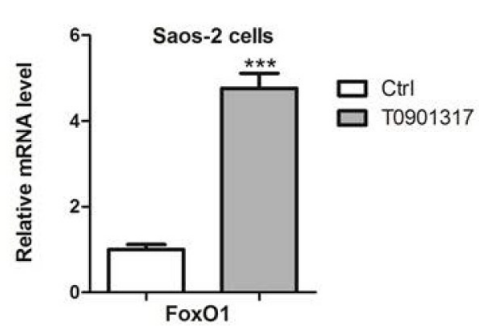

C

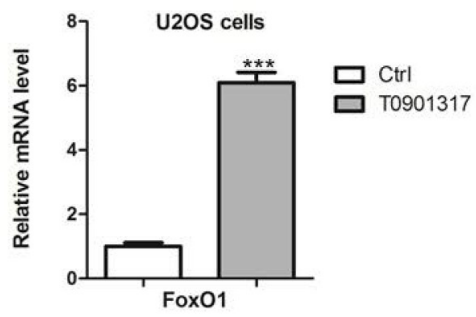

B

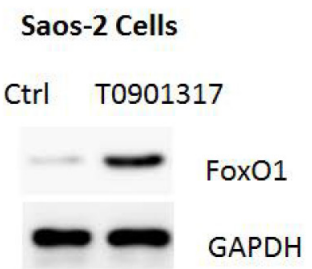

D
Ctrl T0901317

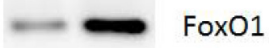

$\longrightarrow$ GAPDH

LXR $\alpha$ deficiency abolished the roles of T0901317 and 22(R)- hydroxycholesterol

Next, endogenous LXR $\alpha$ expression was silenced by small interfering RNA (siRNA) oligos in Saos-2 and U2OS cells (Fig. 2A-2B). As a result, T0901317 and 22(R)-hydroxycholesterol could not exert the anti-proliferative roles in the presence of siRNA oligos targeting LXR $\alpha$ (Fig. 2C-2D), suggesting that the roles of two compounds rely on LXR $\alpha$ expression.

LXR $\alpha$ up-regulated expression of the cell-cycle inhibitors $p 21$ and $p 27$

As LXR $\alpha$ inhibited cell proliferation, we examined its functions on expression of the genes related to cell-cycle regulators, including the CDK inhibitors p27 and p21. Results from real-time PCR and western blot analysis suggested that expression of p27 and p21 were up-regulated in cells treated with T0901317 and 22(R)-hydroxycholesterol, compared to 
Fig. 5. LXR $\alpha$ directly activates Fox01 promoter. (A) Diagram of the LXR $\alpha$-binding site in the human Fox01 promoter (1kb) and two Fox01 luciferase reporters. WT-Luc: wild-type luciferase reporter; Mut-Luc: luciferase reporter carrying point mutations of LXR $\alpha$ binding site. Mutation sites were in bold. (B) Activation of Fox01 luciferase reporters by LXR $\alpha$ in Saos- 2 cells. (C) The binding of T LXR $\alpha$ on the promoter regions of human Fox01 gene were analyzed by ChIP assays and quantified by real-time PCR.
A

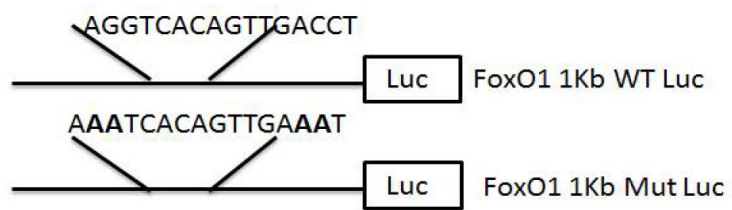

B

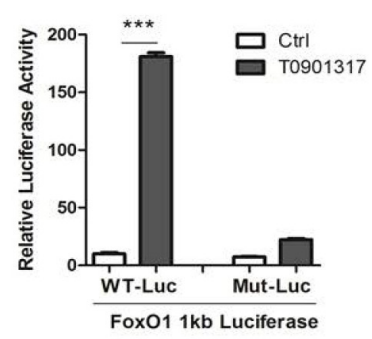

C

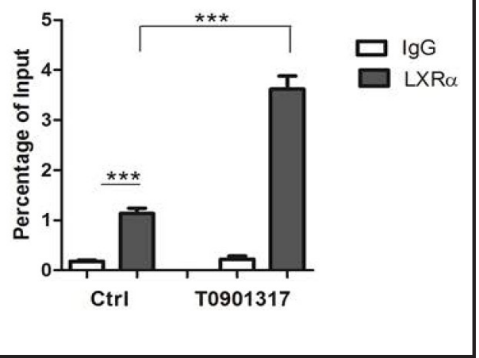

Fig. 6. Expression levels of LXR $\alpha$ in osteosarcoma tissues. (A-B) LXR $\alpha$ expression was determined by real-time PCR and representative western blot in 16 pairs of human osteosarcoma tissues and adjacent noncancerous tissues (Normal).

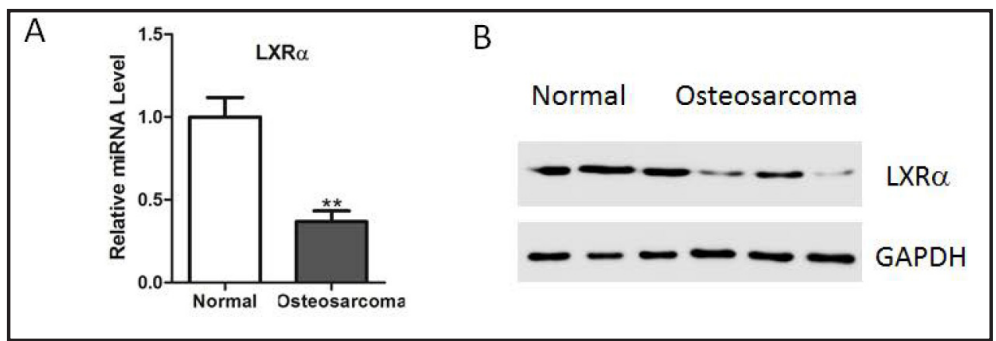

vehicle control treated cells (Fig. 3A-3B). Similar results were also observed in Saos-2 cells (Fig. 3C-3D).

LXR $\alpha$ increased the expression of transcription factor FoxO1 in osterosarcoma cells

Previous studies have revealed that FOXO1 can transcriptionally regulate a series of genes relevant to the cell cycle, including p27 and p21 [15]. In parallel, we found that LXR $\alpha$ activation led to a significant up-regulation of FoxO1 in two osteosarcoma cells (Fig. 4A-4D).

Next, we focused on the molecular mechanism of LXR $\alpha$ regulation of Fox01 transcription. Sequence analysis showed that the promoter region of human Fox01 gene contained a potential LXR $\alpha$ binding site (approximately between -528 and $-515 \mathrm{bp}$ ) (Fig. $5 \mathrm{~A}$ ). Luciferase report assays showed that the transcriptional activity of wild-type Fox01 promoter was dramatically up-regulated by $\mathrm{LXR} \alpha$, whereas the transcriptional activity was abolished in the promoter bearing a mutation in LXR $\alpha$-binding sites (Fig. 5B). Furthermore, our chromatin immunoprecipitaton (ChIP) assays showed that LXR $\alpha$ could uniquely bind to Fox01 promoter (Fig. $5 \mathrm{C}$ ). Besides, the binding of $\mathrm{LXR} \alpha$ to the FoxO1 promoter was also enhanced by T0901317 treatment (Fig. 5C).

\section{LXR $\alpha$ expression levels was reduced in osteosarcoma tissues}

Finally, we examined whether the LXR $\alpha$ was differentially expressed in human osteosarcoma tissues. Its expression level was determined using real-time PCR and western blot in human osteosarcoma tissues and pair-matched adjacent noncancerous tissues. Our results demonstrated that the expression level of LXR $\alpha$ was significantly decreased in osteosarcoma tissues in comparison with the adjacent noncancerous tissues (Fig. 6A and 6B). 
Chang et al.: Liver X Receptor $\alpha$ Inhibits Osteosarcoma Cell Proliferation

\section{Discussion}

In this study, we demonstrate that LXR $\alpha$ expression is down-regulated in osteosarcoma tissues. LXR $\alpha$ activation is able to inhibit cell proliferation in Saos-2 and U2OS cells. Therefore, our study, for the first time, identify that LXR $\alpha$ might be a tumor suppressor in the progression of osteosarcoma.

At the molecular level, our results further revealed that expression of tumor suppressor gene, Fox01, was up-regulated by LXR $\alpha$ activation. LXR $\alpha$ activated FoxO1 mRNA transcription through a direct binding on its promoter region. Fox01 was initially identified during study of the $\mathrm{t}(2,13)(\mathrm{q} 35 ; \mathrm{q} 14)$ and $\mathrm{t}(1,13)(\mathrm{p} 36 ; \mathrm{q} 14)$ chromosomal translocations, which are commonly found in alveolar rhabdomyosarcoma, a skeletal-muscle tumor prevalent in children [16]. Numbers of studies have shown that Fox01 plays critical roles in a variety of biological processes, including cell proliferation, apoptosis, differentiation and stress responses $[16,17]$. At the molecular level, Fox01 could up-regulate the cell-cycle inhibitors p21 and p27, while down-regulate the cell cycle regulator cyclinD1/2, consequently leading to G1/S cell-cycle arrest [18]. Indeed, Fox01 expression or activity was reduced in several types of cancers, including gastric cancer, breast cancer and osteosarcoma [19-23].

Taken together, the key finding of the present study is that LXR $\alpha$ can inhibit the proliferation of osteosarcoma cell lines by up-regulation of Fox01. Understanding the precise role played by LXR $\alpha$ will advance our knowledge of osteosarcoma biology, which may be beneficial for its treatment.

\section{Conflict of Interest}

The authors declare that they have no conflict of Interest.

\section{Acknowledgments}

This work is supported by grant from Natural Science Foundation of Shanghai (13ZR1442500).

\section{References}

1 Akiyama T, Dass CR, Choong PF: Novel therapeutic strategy for osteosarcoma targeting osteoclast differentiation, bone-resorbing activity, and apoptosis pathway. Mol Cancer Ther 2008;7:3461-3469.

2 Savage SA, Mirabello L, Wang Z, Gastier-Foster JM, Gorlick R, Khanna C, Flanagan AM, Tirabosco R, Andrulis IL, Wunder JS, Gokgoz N, Patino-Garcia A, Sierrasesumaga L, Lecanda F, Kurucu N, Ilhan IE, Sari N, Serra M, Hattinger C, Picci P, Spector LG, Barkauskas DA, Marina N, de Toledo SR, Petrilli AS, Amary MF, Halai D, Thomas DM, Douglass C, Meltzer PS, Jacobs K, Chung CC, Berndt SI, Purdue MP, Caporaso NE, Tucker M, Rothman N, Landi MT, Silverman DT, Kraft P, Hunter DJ, Malats N, Kogevinas M, Wacholder S, Troisi R, Helman L, Fraumeni JF Jr, Yeager M, Hoover RN, Chanock SJ: Genome-wide association study identifies two susceptibility loci for osteosarcoma. Nat Genet 2013;45:799-803.

3 Kansara M, Thomas DM: Molecular pathogenesis of osteosarcoma. DNA Cell Biol 2007;26:1-18.

4 Repa JJ, Mangelsdorf DJ: The role of orphan nuclear receptors in the regulation of cholesterol homeostasis. Annu Rev Cell Dev Biol 2000;16:459-481.

5 Calkin AC, Tontonoz P: Transcriptional integration of metabolism by the nuclear sterol-activated receptors lxr and fxr. Nat Rev Mol Cell Biol 2012;13:213-224.

6 Repa JJ, Mangelsdorf DJ: The liver x receptor gene team: Potential new players in atherosclerosis. Nat Med 2002;8:1243-1248. 


\begin{tabular}{|c|c|c|}
\hline Cellular Phy & Cell Physiol Biochem 2013;32:180-186 & \\
\hline and Biochemistry & $\begin{array}{l}\text { DOI: 10.1159/000350134 } \\
\text { Published ontine:. July 1Z, } 2013\end{array}$ & $\begin{array}{l}\text { O } 2013 \text { S. Karger AG, Basel } \\
\text { www.karger.com/cpb }\end{array}$ \\
\hline
\end{tabular}

7 Nagy L, Szanto A, Szatmari I, Szeles L: Nuclear hormone receptors enable macrophages and dendritic cells to sense their lipid environment and shape their immune response. Physiol Rev 2012;92:739-789.

-8 Na TY, Shin YK, Roh KJ, Kang SA, Hong I, Oh SJ, Seong JK, Park CK, Choi YL, Lee MO: Liver x receptor mediates hepatitis b virus x protein-induced lipogenesis in hepatitis b virus-associated hepatocellular carcinoma. Hepatology 2009;49:1122-1131.

-9 Vedin LL, Lewandowski SA, Parini P, Gustafsson JA, Steffensen KR: The oxysterol receptor lxr inhibits proliferation of human breast cancer cells. Carcinogenesis 2009;30:575-579.

10 Chuu CP, Lin HP: Antiproliferative effect of lxr agonists t0901317 and 22(r)-hydroxycholesterol on multiple human cancer cell lines. Anticancer Res 2010;30:3643-3648.

-11 Vedin LL, Gustafsson JA, Steffensen KR: The oxysterol receptors lxralpha and lxrbeta suppress proliferation in the colon. Mol Carcinog 2012; doi: 10.1002/mc.21924.

12 de Boussac H, Pommier AJ, Dufour J, Trousson A, Caira F, Volle DH, Baron S, Lobaccaro JM: Lxr, prostate cancer and cholesterol: The good, the bad and the ugly. Am J Cancer Res 2013;3:58-69.

13 Dufour J, Pommier A, Alves G, De Boussac H, Lours-Calet C, Volle DH, Lobaccaro JM, Baron S: Lack of liver $\mathrm{x}$ receptors leads to cell proliferation in a model of mouse dorsal prostate epithelial cell. PLoS One 2013;8:e58876.

14 Dufour J, Viennois E, De Boussac H, Baron S, Lobaccaro JM: Oxysterol receptors, akt and prostate cancer. Curr Opin Pharmacol 2012;12:724-728.

15 Kloet DE, Burgering BM: The pkb/foxo switch in aging and cancer. Biochim Biophys Acta 2011;1813:19261937.

16 Zhang X, Tang N, Hadden TJ, Rishi AK: Akt, foxo and regulation of apoptosis. Biochim Biophys Acta 2011;1813:1978-1986.

17 Obsil T, Obsilova V: Structural basis for DNA recognition by foxo proteins. Biochim Biophys Acta 2011;1813:1946-1953.

18 Maiese K, Chong ZZ, Shang YC, Hou J: A "foxo" in sight: Targeting foxo proteins from conception to cancer. Med Res Rev 2009;29:395-418.

19 Kim JH, Kim MK, Lee HE, Cho SJ, Cho YJ, Lee BL, Lee HS, Nam SY, Lee JS, Kim WH: Constitutive phosphorylation of the foxo1a transcription factor as a prognostic variable in gastric cancer. Mod Pathol 2007;20:835-842.

-20 Kim SY, Yoon J, Ko YS, Chang MS, Park JW, Lee HE, Kim MA, Kim JH, Kim WH, Lee BL: Constitutive phosphorylation of the foxo1 transcription factor in gastric cancer cells correlates with microvessel area and the expressions of angiogenesis-related molecules. BMC Cancer 2011;11:264.

21 Feng X, Wu Z, Wu Y, Hankey W, Prior TW, Li L, Ganju RK, Shen R, Zou X: Cdc25a regulates matrix metalloprotease 1 through foxo1 and mediates metastasis of breast cancer cells. Mol Cell Biol 2011;31:3457-3471.

22 Yang L, Hu HM, Zielinska-Kwiatkowska A, Chansky HA: Foxo1 is a direct target of ews-fli1 oncogenic fusion protein in ewing's sarcoma cells. Biochem Biophys Res Commun 2010;402:129-134.

-23 Jin S, Pang RP, Shen JN, Huang G, Wang J, Zhou JG: Grifolin induces apoptosis via inhibition of pi3k/akt signalling pathway in human osteosarcoma cells. Apoptosis 2007;12:1317-1326. 